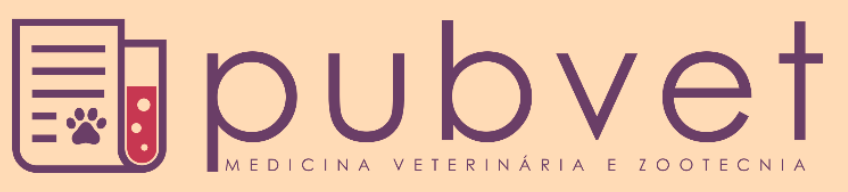

https://doi.org/10.31533/pubvet.v15n09a919.1-13

\title{
Protocolo clínico e tratamento de obesidade canina com alimentação natural caseira: Relato de caso
}

\author{
Giovanna Regina Ferreira Rodrigues ${ }^{1 *} \bullet$, Fabiana Fonseca do Carmo $^{2 \oplus}$ \\ ${ }^{1}$ Graduanda do curso de Medicina Veterinária do Centro Universitário do Planalto Central Apparecido dos Santos - Uniceplac, Gama - DF, Brasil. \\ ${ }^{2}$ Professora Mestre do Curso de Medicina Veterinária do Centro Universitário do Planalto Central Apparecido dos Santos-Uniceplac, Gama-DF, Brasil. \\ *Autor para correspondência, E-mail: giovanna.rfrodrigues3@gmail.com.
}

\begin{abstract}
Resumo. A obesidade canina é uma doença nutricional muito comum na rotina da medicina veterinária. É uma enfermidade de causa multifatorial, caracterizada pelo acúmulo excessivo de gordura corporal no animal. O diagnóstico da obesidade pode ser realizado através da palpação do tecido adiposo, classificação do escore corporal, medidas morfométricas ou pela utilização do cálculo de índice de massa corporal canina, peso corporal relativo e porcentagem de gordura corporal. $\mathrm{O}$ tratamento pode ser realizado pelas dietas para a perda de peso, como a alimentação natural, que é uma dieta caseira balanceada e adequada às exigências nutricionais necessárias para a espécie. Nesse trabalho, foi relatado um cão, macho, castrado, sem raça definida, porte médio, quatro anos de idade, $31 \mathrm{~kg}$, que apresentava sobrepeso e escore de condição corporal 9. Foi prescrita uma dieta natural caseira para tratar a obesidade do animal, que foi acompanhado semanalmente para registro dos resultados. Foi possível observar uma redução de peso gradativa e também mudanças na composição corporal do cão, que obteve redução nas medidas morfométricas e no percentual de gordura. A obesidade, quando não tratada corretamente, pode agravar e causar outras enfermidades.
\end{abstract}

Palavras-chave: Obesidade, dieta natural, nutrição, composição corporal

\section{Clinical protocol and treatment of canine obesity with homemade natural feeding: Case report}

Abstract. Canine obesity is a very common nutritional disease in veterinary medicine. It is a multifactorial caused disease, characterized by excessive accumulation of body fat in dogs. The diagnosis of this condition can be made by palpation of the adipose tissue, classification of the body condition score, morphometric measurements or by using the calculation of the canine body mass index, relative body weight and fat percentage. The treatment can be done by prescription diet for weight loss such as natural feeding, which is a balanced homemade diet that is appropriate to the nutritional needs of the species and can be used to treat obesity. In this research, a male dog was reported, who was castrated, mixed race, medium size, four years old, $31 \mathrm{~kg}$. The dog in question presented overweight characteristics and a body condition score of 9. A natural diet was prescribed to treat the obesity of the animal. The results were analyzed weekly and we were able to observe a reduction in weight, changes in the dog's body composition, reduction in morphometric measurements and fat percentage. Obesity, when not treated correctly, can worsen and cause other diseases.

Keywords: Obesity, natural diet, nutrition, body composition

\section{Introdução}

A nutrição animal é um ramo da medicina veterinária que estuda os nutrientes ideais e essenciais para a sobrevivência dos animais. Nos últimos anos, a nutrição ganhou um grande destaque, já que está 
diretamente relacionada ao bem-estar e à boa saúde dos animais domésticos, os quais necessitam de uma alimentação bem elaborada e de acordo com as exigências nutricionais de cada espécie. Para cães, por exemplo, deve-se seguir as tabelas nutricionais já existentes, que indicam a quantidade e quais nutrientes são essenciais para os indivíduos de acordo com suas características, como: raça, peso, função, estilo de vida, idade etc. (Araújo \& Zanetti, 2019).

A obesidade canina é uma doença nutricional, na qual ocorre o acúmulo excessivo de gordura corporal no animal. Esta enfermidade tem causa multifatorial e compromete o funcionamento do organismo, acarretando uma série de doenças devido ao excesso de peso e tecido adiposo (Jericó et al., 2015). A principal causa da obesidade é o manejo inadequado dos alimentos realizado pelo tutor, o qual, em muitos casos, não consegue identificar facilmente que o seu pet se encontra em uma situação de sobrepeso e então, realiza uma má regulamentação da alimentação, onde a ingestão energética pelo animal é maior que o gasto energético, ou seja, o animal consome, através da alimentação, mais calorias do que gasta. Entre as outras principais causas da doença, pode-se citar: endocrinopatias (hipotireoidismo, hiperadrenocorticismo), genética, uso crônico de medicações, envelhecimento, sedentarismo, castração, predisposição de determinadas raças, sexo e lesões hipotalâmicas (Jericó et al., 2015). Existem estudos que comprovam o fato de que a obesidade é uma enfermidade séria e preocupante, pois acarreta em sérios problemas de saúde, como a diabetes mellitus não insulinodependente, hiperlipidemia, problemas locomotores, neoplasias, hipertensão, problemas reprodutivos, e problemas gástricos (Aptekmann et al., 2014; Silva et al., 2017). A melhor forma de tratar a obesidade é evitando oferecer uma alimentação inadequada para o animal, ou seja, prevenindo a doença. Porém, quando se já tem um animal obeso, pode-se estabelecer protocolos de emagrecimento para restaurar o balanço energético do animal, administrando uma dieta de restrição calórica, por exemplo (Aptekmann et al., 2014; Silva et al., 2017). Para o diagnóstico da obesidade, além da palpação do tecido adiposo extra durante a anamnese, recomenda-se a utilização dos seguintes métodos: Índice de Massa Corporal Canina (IMCC), Peso Corporal Relativo (PCR), Escore de Condição Corporal (ECC), Morfometria e estimativa da Porcentagem de Gordura Corporal (\%GC) (Silva et al., 2017).

O índice de massa corporal canina é uma avaliação adaptada para cães a partir do índice de massa corporal realizado em humanos. Nos humanos, pode-se calcular o índice pela equação peso $(\mathrm{kg}) / \mathrm{altura}(\mathrm{m})$, já nos cães, utiliza-se o peso $(\mathrm{kg})$ e a medida do comprimento da coluna do canino adicionada ao membro pélvico. Tal medida pode ser obtida utilizando-se uma fita métrica, que deve ser posicionada primeiramente na base da nuca do animal, passando em seguida pela região dorsal acima da coluna, logo após, acima da região sacral e, por último, atrás dos membros posteriores, chegando até o solo (Figura 1) (Muller \& Maicon, 2008).

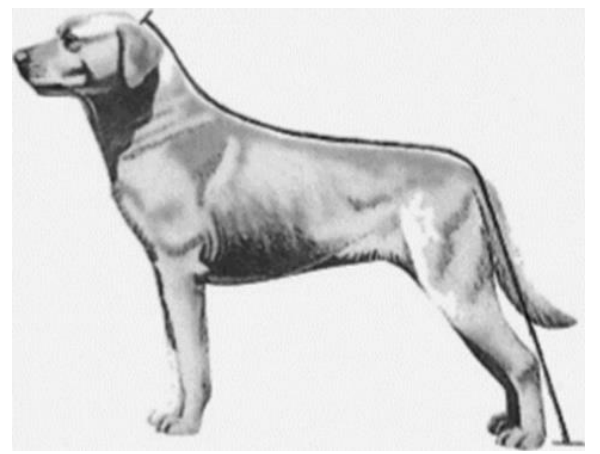

Figura 1. Instrução para medição da estatura de um cão, utilizando fita métrica. Fonte: Muller \& Maicon (2008)

Com o peso em quilos e a medida da estatura em metros, pode-se utilizar a seguinte equação para o cálculo: $\mathrm{IMCC}=$ Peso $(\mathrm{kg}) /$ estatura $^{2}(\mathrm{~m})$. O resultado obtido no cálculo do índice de massa corporal auxilia na análise da condição corporal e na classificação do escore corporal canino, de acordo com a tabela 1.

O peso corporal relativo é a razão entre o peso atual e o peso ideal do animal conforme a equação: PCR $=$ Peso atual / Peso ideal. Se o valor obtido na razão é inferior a 1, pode-se dizer que o canino se encontra abaixo do peso ideal, sé é igual a 1, entende-se que o animal está no peso ideal e caso obtenhase valor acima de 1, significa que o animal apresenta um quadro de sobrepeso (Silva et al., 2017). 
Para cães de raça pura, o peso ideal pode ser obtido de acordo com a característica de peso padrão predefinida para as raças, já para os cães sem raça definida, pode-se utilizar outras medidas de avaliação corporal para obter o peso ideal, como por exemplo, o escore corporal (Rodrigues, 2011).

Tabela 1. Relação entre o índice de massa corporal canina e o escore corporal canino.

\begin{tabular}{lcc}
\hline Condição corporal & Escore & IMCC \\
\hline \multirow{2}{*}{ Abaixo do peso } & 1 & Abaixo de 11,7 \\
\hline Peso ideal & 2 & Entre 11,8 e 15 \\
\hline \multirow{2}{*}{ Acima do peso } & 3 & \\
Obeso & 4 & Entre 15,1 e 18,6 \\
& 5 & Acima de 18,7 \\
\hline
\end{tabular}

Fonte: Rodrigues (2011).

A partir do escore corporal, é possível estimar o percentual de sobrepeso do cão, pois cada ponto do escore equivale de 10 a $15 \%$ de aumento do peso corporal, conforme a tabela 2 . Ou seja, para determinar o peso ideal de um cão, deve-se identificar o escore corporal do animal e então subtrair de seu peso atual, o percentual de sobrepeso (Rodrigues, 2011).

Tabela 2. Relação entre o escore corporal e o percentual de sobrepeso em cães machos e fêmeas.

\begin{tabular}{lcc}
\hline Escore corporal & Percentual de sobrepeso em machos & Percentual de sobrepeso em fêmeas \\
\hline 5 & $17 \%$ & $20 \%$ \\
6 & $22 \%$ & $26 \%$ \\
7 & $26 \%$ & $31 \%$ \\
8 & $31 \%$ & $37 \%$ \\
9 & $35 \%$ & $43 \%$ \\
\hline
\end{tabular}

Fonte: Rodrigues (2011).

O escore de condição corporal é um método de avaliação subjetivo para avaliar a situação da quantidade de gordura e musculatura que compõe o corpo de um determinado animal. A avaliação pode ser realizada através da palpação e inspeção do animal, o que permite a comparação e a pontuação de acordo com as características propostas na escala de escore corporal apresentada visualmente na figura 2 e por escrito na tabela 3 (Rodrigues, 2011).

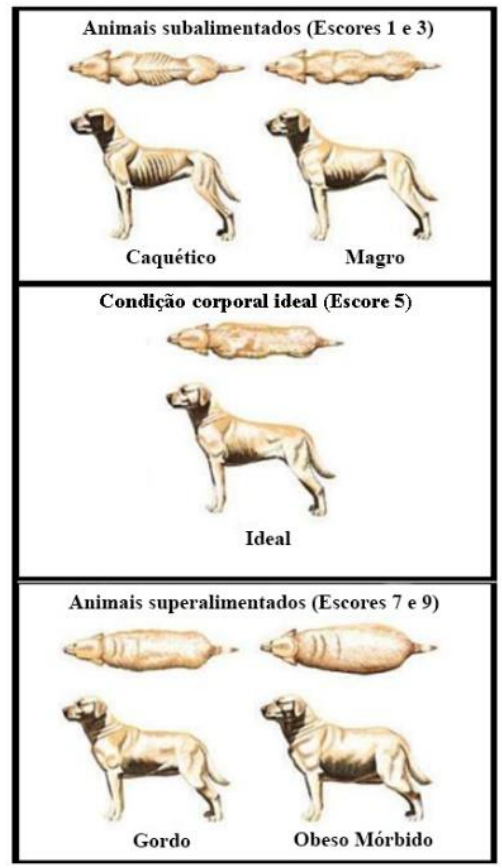

Figura 2. Escala de diferentes escores de condição corporal em cães. Fonte: Rodrigues (2011). 
Tabela 3. Características físicas observadas para avaliação do escore corporal em cães.

\begin{tabular}{|c|c|c|}
\hline Condição & Escore & Características \\
\hline \multirow{4}{*}{ Subalimentados } & 1 & $\begin{array}{l}\text { Costelas, vértebras lombares, ossos pélvicos e todas as proeminências ósseas visíveis à distância. } \\
\text { Ausência de gordura corporal perceptível. Perda evidente de massa muscular. }\end{array}$ \\
\hline & & Costelas, vértebras lombares e ossos pélvicos facilmente visíveis. Ausência de gordura palpável. \\
\hline & 2 & Algumas proeminências ósseas podem estar visíveis. Perda mínima de massa muscular. \\
\hline & 3 & $\begin{array}{l}\text { Costelas facilmente palpáveis e podem estar visíveis sem gordura palpável. Topo das vértebras } \\
\text { lombares visível. Ossos pélvicos visíveis. Cintura e reentrâncias abdominais evidentes. }\end{array}$ \\
\hline \multirow[t]{3}{*}{ Ideal } & 4 & $\begin{array}{l}\text { Costelas facilmente palpáveis com cobertura adiposa mínima. Vista de cima, a cintura é } \\
\text { facilmente observada. Reentrância abdominal evidente. }\end{array}$ \\
\hline & 5 & $\begin{array}{l}\text { Costelas palpáveis sem cobertura adiposa excessiva. Vista de cima, a cintura é observada atrás } \\
\text { das costelas. Abdome retraído quando visto de lado. }\end{array}$ \\
\hline & 6 & $\begin{array}{l}\text { Costelas palpáveis com leve excesso de cobertura adiposa. Vista de cima, a cintura é visível, mas } \\
\text { não é acentuada. Reentrância abdominal aparente. }\end{array}$ \\
\hline \multirow[t]{3}{*}{ Superalimentados } & 7 & $\begin{array}{l}\text { Costelas palpáveis com dificuldade e grossa cobertura adiposa. Depósito de gordura evidente } \\
\text { sobre a área lombar e base da cauda. Ausência de cintura ou sutilmente visível. A reentrância } \\
\text { abdominal pode estar presente. }\end{array}$ \\
\hline & 8 & $\begin{array}{l}\text { Impossível palpar as costelas situadas sob cobertura adiposa muito densa ou palpáveis somente } \\
\text { com pressão acentuada. Denso depósito de gordura sobre a área lombar e base da cauda. Cintura } \\
\text { inexistente. Ausência de reentrância abdominal, podendo existir distensão abdominal evidente. }\end{array}$ \\
\hline & 9 & $\begin{array}{l}\text { Maciços depósitos de gordura sobre o tórax, espinha e base da cauda. Depósitos de gordura no } \\
\text { pescoço e membros. Distensão abdominal evidente. }\end{array}$ \\
\hline
\end{tabular}

Fonte: Laflamme (1997).

A morfometria é avaliada através da medida de determinadas regiões corporais do animal, podendo ser realizada com uma simples fita métrica. As regiões a serem medidas são: a altura da cernelha, o comprimento corporal, os membros pélvicos, o perímetro abdominal, o perímetro torácico e o perímetro da coxa e estão demonstradas na figura 3 abaixo (Guimarães, 2009).

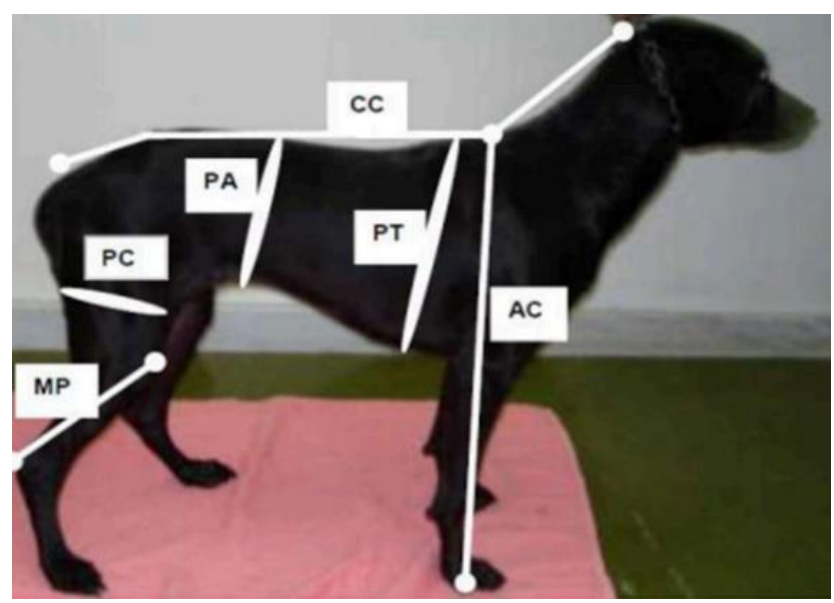

Figura 3. Regiões anatômicas para avaliar as medidas morfométricas dos cães: AC Altura da Cernelha; CC - Comprimento Corporal; PT - Perímetro Torácico; PA - Perímetro Abdominal; PC - Perímetro da coxa; MP - Comprimento do Membro Pélvico. Fonte: Guimarães (2009).

As medidas morfométricas permitem estimar a porcentagem de gordura corporal de um cão através da equação: \% $\mathrm{GC}=(-1,7 \times \mathrm{MP} \mathrm{cm})+(0,93 \times \mathrm{PA} \mathrm{cm})+5$ (Rodrigues, 2011). O percentual de gordura está relacionado com a condição corporal do cão, como descrito na tabela 4.

Tabela 4. Relação entre a condição corporal e o percentual de gordura canino.

\begin{tabular}{lc}
\hline Condição corporal & Percentual de gordura \\
\hline Magro & Abaixo de $10 \%$ \\
Ideal & Entre 10 e $30 \%$ \\
Obeso & Maior que $30 \%$ \\
\hline
\end{tabular}

Fonte: Silva et al. (2017).

Por muitos anos a principal fonte energética dos cães tem sido a ração convencional, composta por grãos secos que contém todos os nutrientes necessários para esses animais e pode ser encontrada 
facilmente em mercados e pet shops. No entanto, há algum tempo, os criadores de cães passaram a ficar mais exigentes em relação à qualidade dos ingredientes utilizados no processo de fabricação desses grãos e então, muitos preferem oferecer aos seus animais, uma dieta natural (Saad \& França, 2010). A alimentação natural é uma opção de dieta caseira que deve ser balanceada e adequada às exigências nutricionais necessárias para a boa saúde dos animais (Tabela 5). Pode ser oferecida aos cães saudáveis por escolha do próprio tutor ou por sugestão de um médico veterinário como forma de tratamento para determinadas afecções (Conceição et al., 2016).

As exigências nutricionais para a espécie canina podem ser determinadas pelo cálculo de necessidade energética de manutenção, no qual possibilita a obtenção da energia metabólica do animal em Kcal/dia. Esse cálculo varia de acordo com idade, atividade física e raça, como descrito na tabela 5 (NRC, 2006).

Tabela 5. Necessidade energética metabólica diária para cães.

\begin{tabular}{|c|c|}
\hline$\overline{\text { Animal }}$ & NEM (kcal por dia) \\
\hline$\overline{\text { Cães adultos jovens e ativos }}$ & $140 \mathrm{kcal} \times(\mathrm{PC} \text { em Kg})^{0,75}$ \\
\hline Cães ativos & $130 \mathrm{kcal} \times\left(\mathrm{PC}\right.$ em kg) ${ }^{0,75}$ \\
\hline Cães terriers ativos & $180 \mathrm{kcal} \times(\mathrm{PC} \text { em kg})^{0,75}$ \\
\hline Cães idosos ativos & $105 \mathrm{kcal} \mathrm{x}\left(\mathrm{PC}\right.$ em kg) ${ }^{0,75}$ \\
\hline Cães inativos & 95 kcal x (PC em kg) 0,75 \\
\hline
\end{tabular}

NEM - Energia metabólica necessária; PC - Peso Corporal. Fonte: NRC (2006).

Alergias alimentares, doenças hepáticas, endocrinopatias, síndrome da má absorção, neoplasias, alterações renais, e obesidade estão entre as afecções nas quais a alimentação natural pode ser considerada como aliada durante o tratamento das mesmas, já que este tipo de dieta pode ser personalizado de maneira específica para cada paciente e suas exigências nutricionais (Conceição et al., 2016).

O objetivo desse trabalho foi avaliar a composição corporal de um cão diagnosticado com obesidade e após, tratamento com a implementação de uma dieta caseira composta de ingredientes naturais.

\section{Relato de caso}

Foi realizado um estudo de caso em um cão, macho, castrado, sem raça definida, porte médio, quatro anos de idade, $31 \mathrm{~kg}$, iniciado em agosto de 2020. Segundo informações dos tutores, o animal apresentava, letargia, possuía vacinas e vermífugo atualizados e foi diagnosticado, há cerca de dois anos, com displasia coxofemoral, enfermidade na qual se apresentou em grau D durante o período do estudo. O cão reside em casa com quintal, não possui frequência de passeios e atividade física, e sua alimentação era realizada duas vezes ao dia, às $8 \mathrm{~h}$ e às $19 \mathrm{~h}$ e era composta por 100 gramas de frango cozido e 120 gramas de ração seca premium de baixo teor calórico para cães adultos com sobrepeso, cujo objetivo era a redução de peso. Além da dieta hiper proteica devido à adição de carne de frango, também eram oferecidos petiscos diariamente ao cão.

No exame físico realizado, foi possível observar que o animal apresentava sobrepeso, mucosas normocoradas, linfonodos em situação anatômica normal, ausculta cardíaca sem alterações e normotermia. Também foi realizada uma avaliação para o diagnóstico de obesidade, onde foi observado escore de condição corporal 9, índice de massa corporal canina 27,8, estimativa da porcentagem de gordura corporal de $39,82 \%$, peso ideal de $20 \mathrm{~kg}, \mathrm{AC}=47 \mathrm{~cm}, \mathrm{CC}=65 \mathrm{~cm}, \mathrm{PT}=80 \mathrm{~cm}, \mathrm{PA}=74 \mathrm{~cm}$, $\mathrm{PC}=32 \mathrm{~cm}, \mathrm{MP}=20 \mathrm{~cm}$ e peso corporal relativo de 1,56 .

Foram solicitados exames laboratoriais e complementares antes e após a mudança nos hábitos alimentares do cão, com objetivo de adotar um protocolo de formulação de dieta caseira, identificar possíveis causas da obesidade, alterações causadas por essa enfermidade e alterações e ou melhorias causadas pela troca da dieta. Entre esses exames, foram realizados: hemograma completo, bioquímicos, urinálise de rotina, ultrassom abdominal, radiografia da região pélvica com incidência ventrodorsal e laterolateral. Também foi dosada a glicemia do animal, que se apresentou dentro da normalidade.

Após a realização dos exames iniciais, foi prescrita uma dieta caseira natural formulada para o tratamento do sobrepeso, na qual foi balanceada de acordo com a necessidade metabólica do paciente. 
A princípio, no dia 8 de setembro, foi iniciada a fase de adaptação, introduzindo $50 \%$ da quantidade da nova dieta natural e $30 \%$ da quantidade de ração já oferecida anteriormente.

A composição da dieta foi calculada seguindo a porcentagem disponível no modelo de dieta para cães obesos descrita pela USDA, conforme a tabela 6:

Tabela 6. Plano alimentar para cães obesos com composição de ingredientes naturais.

\begin{tabular}{lclc}
\hline Composição & \% da MS & Fórmula & \% da matéria original \\
\hline Proteína Bruta & 30,75 & Arroz cozido & 40 \\
Carboidrato & 53,95 & Músculo magro bovino ou peito de frango & 15 \\
Extrato Etéreo & 6,41 & Fígado bovino & 5 \\
Fibra Bruta & 4,74 & Cenoura & 15 \\
Matéria Mineral & 4,09 & Vagem & 23 \\
Umidade & 63,34 & & \\
Cálcio & 0,81 & & 1 \\
Fósforo & 0,59 & Suplemento mineral e vitamínico & 0,1 \\
& & Sal & \\
\hline
\end{tabular}

Fonte: Halfen et al. (2017).

A quantidade de alimentos utilizada na fase de adaptação está descrita na tabela 7 abaixo e foi determinada a partir do resultado do cálculo da necessidade energética metabólica do animal, que resultou em 1.248 Kcal por dia. A nova dieta foi administrada ao animal duas vezes ao dia. A fase de adaptação durou quinze dias e foi iniciada então, no dia 22 de setembro, uma nova dieta, na qual toda a ração seca foi eliminada, passando a ser composta de alimentos naturais, suplementação mineral e vitamínica. O novo plano alimentar foi calculado com base em um novo peso e necessidade metabólica do animal (1.156 Kcal/dia), conforme descrito na tabela 7 abaixo:

Tabela 7. Quantidade diária de alimentos ofertados ao animal durante a fase de adaptação e durante a dieta natural caseira.

\begin{tabular}{lcc}
\hline Alimento & Quantidade durante fase de adaptação, g & Quantidade diária da dieta natural, g \\
\hline Arroz integral cozido & 125 & 230 \\
Carne bovina & 62,5 & 115 \\
Fígado bovino & 15,6 & 28 \\
Cenoura e beterraba & 46,75 & 86 \\
Vagem & 71,25 & 123 \\
Ração seca & 40 & - \\
Suplemento mineral e vitamínico & - & 2,5 \\
Sal & - & 0,30 \\
\hline
\end{tabular}

A quantidade total de alimentos foi dividida em duas porções e oferecida ao animal duas vezes por dia. Os alimentos da dieta foram cozidos separadamente, pesados conforme a prescrição em uma balança de precisão, após, foram armazenados em sacos plásticos e congelados (Figura 4). Após, a porção foi descongelada, requentada em um forno micro-ondas e oferecida ao cão em seu horário de alimentação (Figura 5). A nova dieta foi bem aceita por parte do cão, o que tornou desnecessária uma mudança de ingredientes.

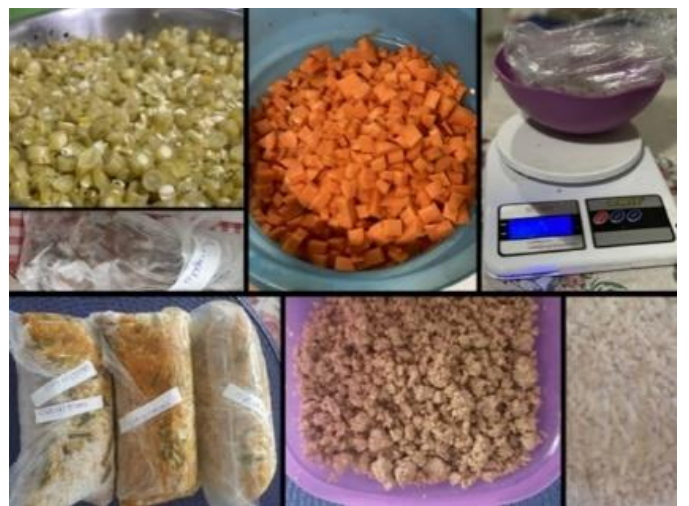

Figura 4. Processo de preparo da dieta natural caseira.

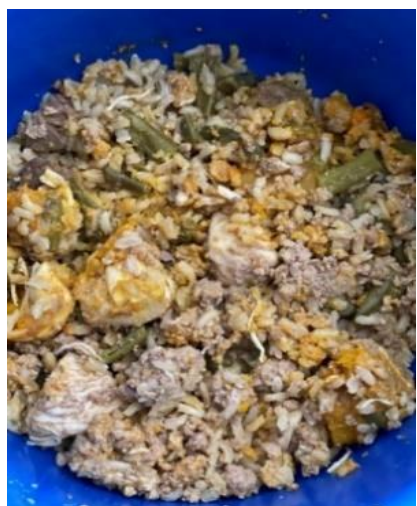

Figura 5. Refeição natural caseira ofertada ao animal. 


\section{Resultados}

No eritrograma inicial e final do animal, descrito na tabela 9 abaixo, pode-se observar resultados dentro dos valores de referência para a espécie, apresentando hemácias normocíticas e normocrônicas.

Tabela 7. Resultados observados no eritrograma completo realizado no animal.

\begin{tabular}{lccc}
\hline Tipo de exame & $\begin{array}{c}\text { Resultado inicial } \\
(22 \text { ago. 2020) }\end{array}$ & $\begin{array}{c}\text { Resultado final } \\
(9 \text { nov. 2020) }\end{array}$ & $\begin{array}{c}\text { Valores de } \\
\text { referência }\end{array}$ \\
\hline Hemácias & 07,30 milhões $/ \mathrm{mm}^{3}$ & 8,09 milhões $/ \mathrm{mm}^{3}$ & 5,50 a $8,50 \mathrm{milhões} / \mathrm{mm}^{3}$ \\
Hemoglobina & $17,20 \mathrm{~g} / \mathrm{dl}$ & $17,90 \mathrm{~g} / \mathrm{dl}$ & $12,00 \mathrm{a} 18,00 \mathrm{~g} / \mathrm{dl}$ \\
Hematócrito & $51,00 \%$ & $54 \%$ & $37,00 \mathrm{a} 55,00 \%$ \\
Vol. Cor. Médio & $69,86 \mathrm{fl}$ & $66,75 \mathrm{fl}$ & $60,00 \mathrm{a} 72,00 \mathrm{fl}$ \\
Hem. Cor. Médio & $23,56 \mathrm{pg}$ & $22,13 \mathrm{pg}$ & $21,00 \mathrm{a} 26,00 \mathrm{pg}$ \\
Conc. Hemogl. Médio & $33,73 \mathrm{~g} / \mathrm{dl}$ & $33,15 \mathrm{~g} / \mathrm{dl}$ & $31,00 \mathrm{a} 26,00 \mathrm{~g} / \mathrm{dl}$ \\
\hline
\end{tabular}

No primeiro leucograma realizado, foi possível identificar uma leve neutrofilia relativa, pois os neutrófilos segmentados, encontraram-se superior ao valor de referência na primeira mensuração. Os outros resultados apresentaram-se normais. O segundo leucograma apresentou valores dentro do padrão de referência para a espécie (Tabela 10).

Tabela 8. Resultados observados no leucograma realizado no animal.

\begin{tabular}{|c|c|c|c|c|c|c|}
\hline Tipo de exame & \multicolumn{2}{|c|}{$\begin{array}{c}\text { Resultado Inicial } \\
(22 \text { ago. } 2020)\end{array}$} & \multicolumn{2}{|c|}{$\begin{array}{c}\text { Resultado final } \\
(9 \text { nov. } 2020)\end{array}$} & \multicolumn{2}{|c|}{ Valores de referência } \\
\hline \multirow[t]{2}{*}{ Leucócitos } & \multicolumn{2}{|c|}{$10.300 \mathrm{~mm}^{3}$} & \multicolumn{2}{|c|}{$10.400 \mathrm{~mm}^{3}$} & \multicolumn{2}{|c|}{6.000 a $17.000 \mathrm{~mm}^{3}$} \\
\hline & \multicolumn{2}{|c|}{ Relativo Absoluto } & Relativo & Absoluto & Relativo & Absoluto \\
\hline Bastonetes & $0 \%$ & $0.000 / \mathrm{mm}^{3}$ & $0 \%$ & $0.000 / \mathrm{mm}^{3}$ & 0 a $3 \%$ & 0 a $510 / \mathrm{mm}^{3}$ \\
\hline Segmentados & $79 \%$ & $8.137 / \mathrm{mm}^{3}$ & $65 \%$ & $6.760 / \mathrm{mm}^{3}$ & 60 a $77 \%$ & 3.600 a $13.090 / \mathrm{mm}^{3}$ \\
\hline Eosinófilos & $6 \%$ & $0.618 / \mathrm{mm}^{3}$ & $3 \%$ & $0.312 / \mathrm{mm}^{3}$ & 0 a $10 \%$ & 0 a $1.700 / \mathrm{mm}^{3}$ \\
\hline Linfócitos & $13 \%$ & $1.339 / \mathrm{mm}^{3}$ & $27 \%$ & $2.808 / \mathrm{mm}^{3}$ & 12 a $30 \%$ & 720 a $5.100 / \mathrm{mm}^{3}$ \\
\hline Monócitos & $2 \%$ & $0,206 / \mathrm{mm}^{3}$ & $5 \%$ & $0.520 / \mathrm{mm}^{3}$ & 1 a $10 \%$ & $0 \mathrm{a} 1.700 / \mathrm{mm}$ \\
\hline Basófilos & $0 \%$ & $0,000 / \mathrm{mm}^{3}$ & $0 \%$ & $0.000 / \mathrm{mm}^{3}$ & Raros & Raros \\
\hline Outros dados & \multicolumn{2}{|c|}{ Resultado Inicial } & \multicolumn{2}{|c|}{ Resultado Final } & \multicolumn{2}{|c|}{ Valores de referência } \\
\hline Proteínas Plasmáticas & \multicolumn{2}{|c|}{$8 \mathrm{~g} / \mathrm{dl}$} & \multicolumn{2}{|c|}{$7,5 \mathrm{~g} / \mathrm{dl}$} & \multicolumn{2}{|c|}{6 a $8 \mathrm{~g} / \mathrm{dl}$} \\
\hline Plaquetas & \multicolumn{2}{|c|}{$236.000 / \mathrm{mm}^{3}$} & \multicolumn{2}{|c|}{$200.000 / \mathrm{mm}^{3}$} & \multicolumn{2}{|c|}{180.000 a $500.000 / \mathrm{mm}^{3}$} \\
\hline Pesquisa de hemoparasita & \multicolumn{2}{|c|}{ Negativo } & \multicolumn{2}{|c|}{ Negativo } & \multicolumn{2}{|c|}{ Negativo } \\
\hline
\end{tabular}

Os exames de bioquímica sérica, descritos na tabela 11, se apresentaram, em sua maioria, dentro dos padrões de referência para a espécie canina, exceto pelos triglicerídeos e lipídeos totais, que estavam aumentados e o cálcio, que se estava reduzido. Já na segunda mensuração, ocorreu o aumento da fosfatase alcalina, o cálcio continuou reduzido, os triglicerídeos e lipídeos estavam dentro dos padrões.

Tabela 9. Resultados observados no exame de bioquímica sérica realizado no animal

\begin{tabular}{|c|c|c|c|}
\hline Tipo de exame & $\begin{array}{l}\text { Resultado Inicial } \\
\text { (22 ago. de 2020) }\end{array}$ & $\begin{array}{l}\text { Resultado Final } \\
(9 \text { nov. de 2020) }\end{array}$ & Valores de referência \\
\hline$\overline{\text { Colesterol }}$ & $227 \mathrm{mg} / \mathrm{dl}$ & $245 \mathrm{mg} / \mathrm{dl}$ & 135 a $270 \mathrm{mg} / \mathrm{dl}$ \\
\hline Triglicérides & $368 \mathrm{mg} / \mathrm{dl}$ & $99 \mathrm{mg} / \mathrm{dl}$ & 20 a $112 \mathrm{mg} / \mathrm{dl}$ \\
\hline Lipídeos totais & $967 \mathrm{mg} / \mathrm{dl}$ & $585,50 \mathrm{mg} / \mathrm{dl}$ & 400 a $960 \mathrm{mg} / \mathrm{dl}$ \\
\hline Cálcio & $8,3 \mathrm{mg} / \mathrm{dl}$ & $6,7 \mathrm{mg} / \mathrm{dl}$ & 9 a $11 \mathrm{mg} / \mathrm{dl}$ \\
\hline Potássio & $4,50 \mathrm{mmol} / \mathrm{L}$ & $4,6 \mathrm{mmol} / \mathrm{L}$ & 3,7 a $5,8 \mathrm{mmol} / \mathrm{L}$ \\
\hline Sódio & $151,1 \mathrm{mmol} / \mathrm{L}$ & $145 \mathrm{mmol} / \mathrm{L}$ & 141 a $153 \mathrm{mmol} / \mathrm{L}$ \\
\hline Creatinina & $1,1 \mathrm{mg} / \mathrm{dl}$ & $1,5 \mathrm{mg} / \mathrm{dl}$ & 0,5 a $1,5 \mathrm{mg} / \mathrm{dl}$ \\
\hline Fosfatase Alcalina & $58 \mathrm{U} / \mathrm{L}$ & $270 \mathrm{U} / \mathrm{L}$ & 20 a $150 \mathrm{U} / \mathrm{L}$ \\
\hline Ureia & $42 \mathrm{mg} / \mathrm{dl}$ & $34 \mathrm{mg} / \mathrm{dl}$ & 21 a $60 \mathrm{mg} / \mathrm{dl}$ \\
\hline
\end{tabular}

$\mathrm{Na}$ análise da urina do animal, foi possível observar volume, cor, odor e densidade dentro dos padrões normais, sem a presença de sangue oculto, proteínas, glicose, corpos cetônicos ou bilirrubina na amostra. $\mathrm{O}$ aspecto estava turvo, com presença de hemácias e o pH estava abaixo do valor de referência (Tabela 12).

Na primeira ultrassonografia (Figura 6) foi possível observar que as glândulas adrenais estavam sutilmente aumentadas de tamanho. Já na segunda ultrassonografia (Figura 7), as glândulas adrenais estavam dentro da normalidade e o fígado estava aumentado de tamanho (Figura 8). 
Tabela 10. Resultados observados no exame de urinálise de rotina realizado através de cistocentese no animal.

\begin{tabular}{lccc}
\hline Tipo de exame & Resultado Inicial (22 ago. 2020) & Resultado final (9 nov. 2020) & Valores de referência \\
\hline Urinálise & & & - \\
Volume & $11 \mathrm{ml}$ & $8,5 \mathrm{ml}$ & Amarelo \\
Cor & Amarelo & Amarelo & Sui generis \\
Odor & Sui generis & Sui generis & Límpido \\
Aspecto & Turvo $(+)(+)($ ) & Turvo $(+)($ ) $)$ & $1.020-1.045$ \\
Densidade & 1.045 & 1.035 & 5,5 a 6,5 \\
Ph & 5 & 5 & Negativo \\
Sangue oculto & Negativo & Negativo & Negativo/Traços \\
Proteínas & Negativo & Traços & Negativo \\
Glicose & Negativo & Negativo & Negativo \\
Corpos cetônicos & Negativo & Negativo & Negativo \\
Bilirrubina & Negativo & Negativo &
\end{tabular}

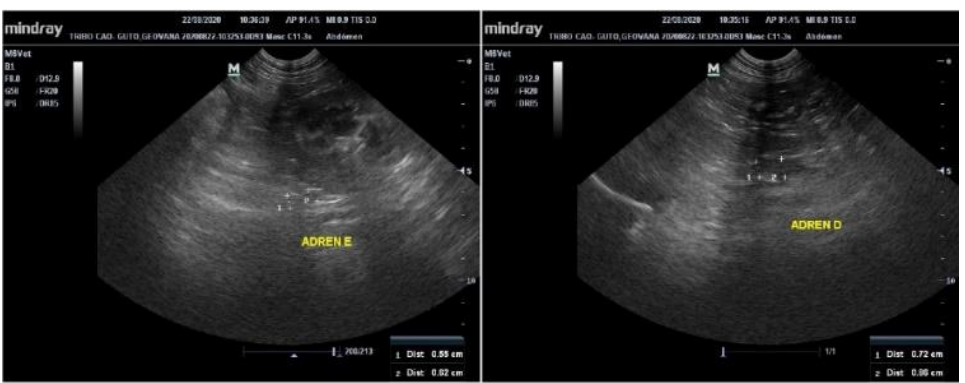

Figura 6. Imagem de ultrassonografia indicando discreto aumento de glândulas adrenais (22 de agosto de 2020).

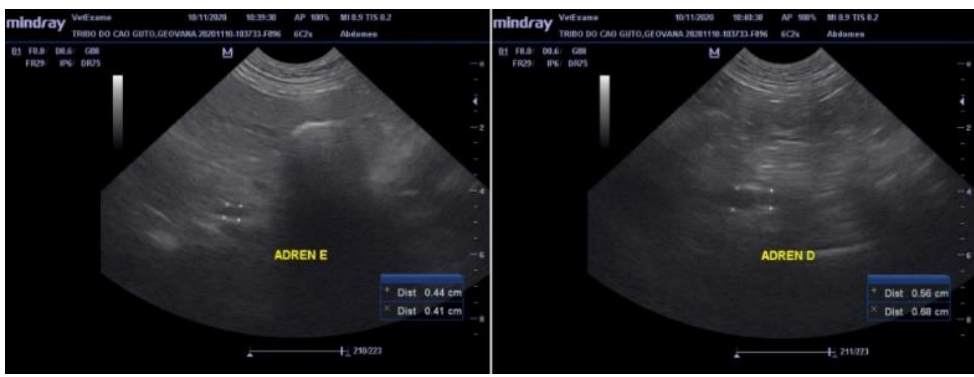

Figura 7. Imagem de ultrassonografia indicando tamanho normal de glândulas adrenais (10 de novembro de 2020).
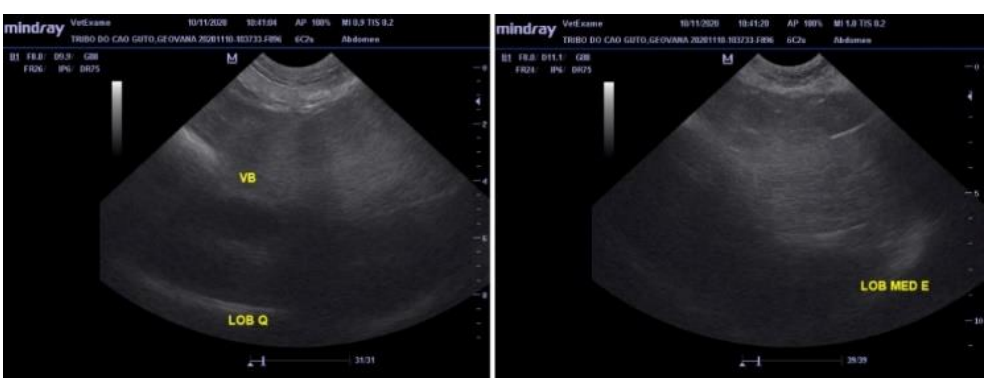

Figura 8. Imagem de ultrassonografia indicando alteração sugestiva de hepatomegalia (10 de novembro de 2020).

Na radiografia (Figura 9), pode-se observar, através de uma incidência ventrodorsal, que existe a presença de uma alteração óssea: a displasia coxofemoral. No laudo médico, consta que a alteração pode ser caracterizada por grau $\mathrm{D}$ e descreve como achados radiográficos o acentuado aumento da lassitude articular, incongruência articular coxofemoral bilateral, presença de subluxação, remodelamento das cabeças femorais, espessamento dos colos femorais, raseamento acetabular e osteófitos pericondriais bilateral.

Durante a administração da nova dieta, o animal foi acompanhado semanalmente para controle do peso em jejum, escore de condição corporal, IMCC, PCR e \%GC, como descrito na tabela 13. Também 
foram mensuradas, semanalmente, as medidas morfométricas do animal, como descrito na tabela $14 \mathrm{e}$ mostrado nas figuras 10 e $\underline{11}$.

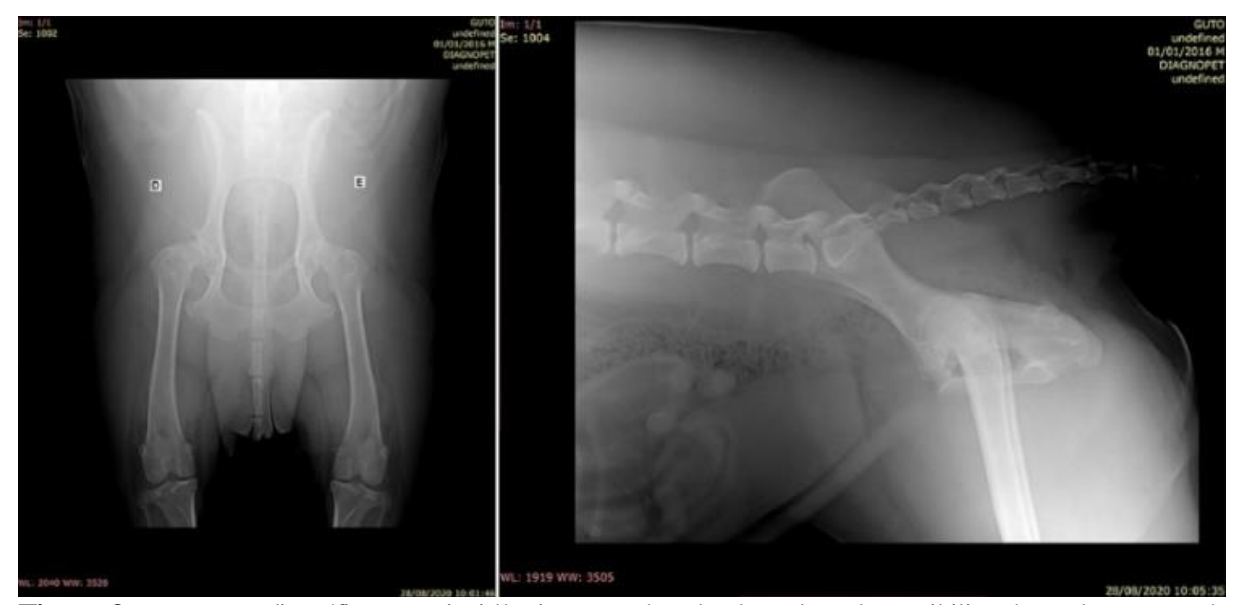

Figura 9. Imagem radiográfica com incidência ventrodorsal e laterolateral, possibilitando a observação de displasia coxofemoral.

Tabela 11. Evolução semanal do peso, escore de condição corporal, IMCC, PCR e \%GC durante o tratamento de sobrepeso com alimentação natural caseira.

\begin{tabular}{lccccc}
\hline Data & Peso, kg & IMCC & ESCORE & PCR & GC, $\%$ \\
\hline $08 / 09$ & 31,2 & 27,8 & 9 & 1,56 & 39,82 \\
$15 / 09$ & 30,0 & 26,8 & 9 & 1,50 & 38,89 \\
$22 / 09$ & 28,0 & 25,0 & 8 & 1,40 & 37,03 \\
$29 / 09$ & 29,5 & 26,3 & 8 & 1,47 & 36,1 \\
$06 / 10$ & 26,4 & 8 & 1,48 & 36,1 \\
$13 / 10$ & 29,6 & 26,3 & 8 & 1,47 & 34,24 \\
$20 / 10$ & 29,5 & 26,2 & 8 & 1,47 & 33,31 \\
$27 / 10$ & 29,4 & 25,3 & 7 & 1,42 & 31,45 \\
$03 / 11$ & 28,4 & 25,4 & 7 & 1,43 & 30,52 \\
$10 / 11$ & 28,5 & 24,9 & 7 & 1,39 & 28,6 \\
$17 / 11$ & 27,9 & 24,7 & 7 & 1,39 & 28,6 \\
\hline
\end{tabular}

IMCC - Índice de Massa Corporal Canina; PCR - Peso corporal relativo; \%GC - Porcentagem de Gordura Corporal.

Além das mudanças já relatadas com a implementação da nova dieta, o cão apresentou pelagem com aspecto mais brilhoso, bem como uma redução na queda dos pelos. Além disso, ocorreu aumento na frequência de evacuação e redução do volume das fezes, que se tornaram menos fétidas, com aspecto pastoso, porém com formato (Figura 12).

Tabela 12. Evolução semanal da morfometria do animal durante o tratamento de sobrepeso com alimentação natural caseira.

\begin{tabular}{lcccccc}
\hline DATA & CC, $\mathrm{cm}$ & $\mathrm{AC}, \mathrm{cm}$ & $\mathrm{PT}, \mathrm{cm}$ & $\mathrm{PA}, \mathrm{cm}$ & $\mathrm{PC}, \mathrm{cm}$ & $\mathrm{MP}, \mathrm{cm}$ \\
\hline $08 / 09$ & 65 & 47 & 80 & 74 & 32 & 20 \\
$15 / 09$ & 65 & 47 & 79 & 73 & 30 & 20 \\
$22 / 09$ & 65 & 47 & 78 & 71 & 30 & 20 \\
$29 / 09$ & 65 & 47 & 78 & 70 & 30 & 20 \\
$06 / 10$ & 65 & 47 & 77 & 70 & 29 & 20 \\
$13 / 10$ & 65 & 47 & 77 & 68 & 28 & 20 \\
$20 / 10$ & 65 & 47 & 76 & 67 & 27 & 20 \\
$27 / 10$ & 65 & 47 & 75 & 65 & 27 & 20 \\
$03 / 11$ & 65 & 47 & 74 & 64 & 26 & 20 \\
$10 / 11$ & 65 & 47 & 74 & 62 & 26 & 20 \\
$17 / 11$ & 65 & 47 & 72 & 62 & 26 & 20 \\
\hline
\end{tabular}

CC - Comprimento Corporal; AC - Altura da Cernelha; PT - Perímetro Torácico; PA - Perímetro Abdominal; PC - Perímetro da Coxa; MP - Comprimento do Membro Pélvico. 


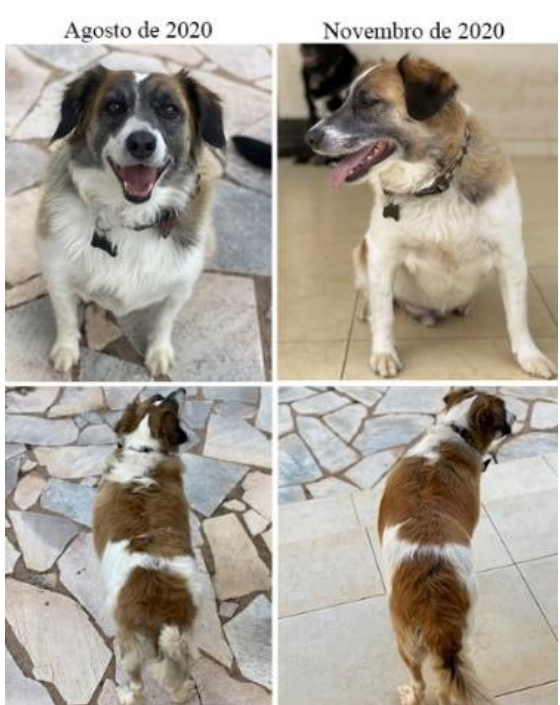

Figura 10. Composição corporal do cão durante o tratamento com dieta natural caseira (agosto e novembro de 2020). Posição cranial e caudal.

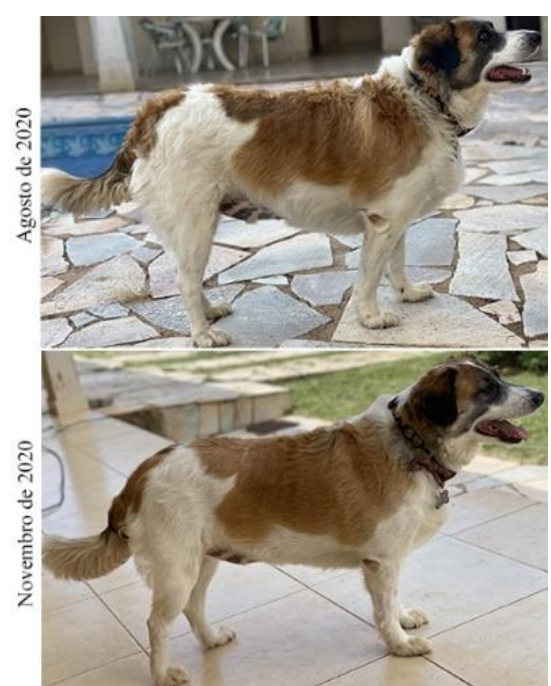

Figura 11. Composição corporal do cão durante o tratamento com dieta natural caseira (agosto e novembro de 2020). Posição lateral.

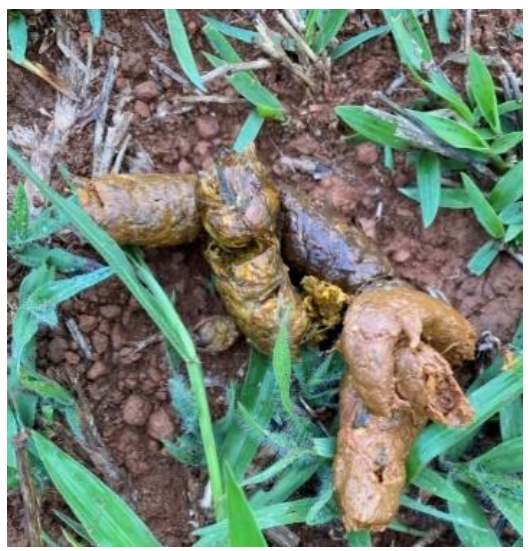

Figura 12. Aspecto das fezes do animal após a mudança nos hábitos alimentares.

O cão, que anteriormente apresentou-se letárgico, passou a ser mais ativo após a mudança de hábitos alimentares e perda parcial do sobrepeso.

\section{Discussão}

A obesidade é o distúrbio nutricional mais diagnosticado em cães na rotina de clínicas veterinárias e isso pode estar associado as causas multifatoriais da doença. Segundo Aptekmann et al. (2014), a prevalência de casos da doença está em fase crescente, juntamente com a prevalência de casos da mesma enfermidade em humanos.

No leucograma do animal, foi possível identificar uma neutrofilia relativa, alteração na qual pode ser causada por estresse agudo ocasionado por medo, mudança de ambiente, transporte, dor e outros fatores. $\mathrm{O}$ aumento dos neutrófilos está relacionado à liberação de catecolaminas, que são secretadas após o momento do estresse (Garcia-Navarro \& Pachaly, 1994; Kantek \& Navarro, 2005; Rebar et al., 2003).

O aumento de triglicerídeos e lipídeos totais, segundo especulações de alguns autores, pode ser causado pela obesidade (Brunetto et al., 2011); porém, é importante ressaltar a existência de outros fatores que acarretam em hiperlipidemia, como uma dieta com alto teor de gordura, por exemplo (Camargo, 2017). Em uma segunda mensuração, os triglicerídeos e lipídeos encontraram-se dentro dos valores normais para a espécie, portanto, entende-se que tal redução ocorreu devido à administração de uma nova dieta com baixa composição de gordura. 
No exame de ultrassom, as glândulas adrenais apresentaram-se aumentadas de tamanho para a espécie e porte do animal. Todavia, de acordo com Moreira (2009) e Rosa et al. (2011) o cão não apresentava sinais clínicos característicos de hiperadrenocorticismo (polidipsia, poliúria, abaulamento abdominal, hiperpigmentação cutânea, alopecia, fraqueza, letargia etc.). Na segunda avaliação de ultrassonografia, foi observado um quadro de hepatomegalia, juntamente com o aumento da fosfatase alcalina nos exames bioquímicos, o que pode ser indicativo de presença de infiltrado gorduroso no fígado do animal. Não foram realizados exames específicos para investigar a causa e se essas alterações estão relacionadas aos novos hábitos alimentares.

A hipocalcemia observada não foi investigada, porém pode-se levantar a suspeita, além da mudança de dieta, de que o animal apresente algum distúrbio como causa desta, já que, na dieta prescrita, foi seguida a recomendação diária de suplementação de cálcio prevista por Carciofi (2008). Entre as principais causas suspeitas, está o hipoparatireoidismo, endocrinopatia na qual será investigada posteriormente e pode, inclusive, ser causa da obesidade caso seja diagnosticada (Cardoso et al., 2015).

Após a implementação da dieta, foi possível observar uma redução de peso de $31,2 \mathrm{~kg}$ para $27,7 \mathrm{~kg}$ no período de três meses. Além da redução do peso, ocorreram mudanças na composição corporal do cão, onde o percentual de gordura e as medidas morfométricas obtiveram uma redução significativa, possibilitando a classificação do escore corporal canino de número sete (Cordão et al., 2021).

Em um estudo de caso realizado por Goslar et al. (2016), no qual uma cadela foi submetida ao mesmo plano alimentar deste relato, também houve redução de peso e medidas, porém essas alterações não foram tão significativas devido ao pouco esforço de seu tutor em aplicar o protocolo de emagrecimento. O mesmo ocorreu no estudo de Carciofi (2005), onde o autor realizou um estudo com vários cães de tutores diferentes e, nos casos em que os tutores seguiram rigorosamente o protocolo, os resultados observados foram mais significativos. Nos casos em que os resultados foram pouco satisfatórios, constatou-se a dificuldade em fazer com que os tutores seguissem impecavelmente a formulação, a dificuldade no manejo e formulação de protocolo que atendam às exigências nutricionais e o alto custo da dieta natural caseira.

O acréscimo de fibras contidas no arroz integral e na vagem presentes na dieta do animal também foi de grande importância para o emagrecimento, pois, de acordo com Roque et al. (2006), estes ingredientes atuam retardando o esvaziamento gástrico, o que possibilita maior tempo de saciedade. Além disso, diminuem a absorção de gorduras e glicose pelo intestino do animal, o que colabora com a redução da concentração de colesterol.

A pelagem do animal e as fezes, após a alteração dos hábitos alimentares, sofreram mudanças: a pelagem passou a ter brilho mais intenso e a queda dos fios foi reduzida; o cão passou a ter maior frequência de evacuação, o volume das fezes foi reduzido, as fezes apresentaram odor menos fétido e aspecto mais pastoso, porém com formato. De acordo com os estudos de Araújo et al. (2018) essas alterações são frequentes em cães que tem alimentação natural em suas rotinas.

Os sinais clínicos da displasia coxofemoral podem ser agravados com a presença do sobrepeso, causando maior desconforto ao animal, que se apresentou letárgico e menos ativo de modo geral (Firmino et al., 2020). Após a mudança de hábitos alimentares e redução do sobrepeso, o animal passou a sentir menos desconforto, o que, provavelmente, o tornou mais ativo e interessado em atividades recreativas.

A dificuldade de preparo da dieta natural, o alto custo dos ingredientes comparado à ração convencional, a dificuldade de manejo e a rejeição dos alimentos pelos animais são pontos negativos deste tipo de alimentação (Carciofi, 2005), bem como as medidas higiênicas antes, após e durante o momento de preparo da dieta natural caseira, que devem ser aplicadas rigorosamente, já que são essenciais para evitar uma possível infecção do animal por doenças infecciosas e parasitárias ( $\underline{\operatorname{Saad} \&}$ França, 2010).

A dieta natural é uma maneira dos cães se aproximarem de seus ancestrais selvagens, que se alimentavam de pequenas presas, carniça, frutas e raízes, porém vale ressaltar que tal dieta deve ser balanceada e calculada de acordo com as exigências nutricionais para a espécie e deve ser elaborada preferencialmente por um profissional da área de nutrição animal, para evitar a ocorrência de algum 
problema nutricional relacionado a necessidade de nutrientes diária dos cães, como a carência ou excesso de minerais, vitaminas, proteínas, carboidratos e lipídeos.

\section{Conclusão}

O presente trabalho permite concluir que a alimentação natural caseira foi uma considerável aliada para o tratamento de perda de peso do animal estudado, já que interferiu em uma melhora da composição e condição corporal, bem como na redução de lipídeos e triglicerídeos.

O tratamento de perda de peso em cães depende principalmente da colaboração do dono para se obter sucesso, por tanto, deve-se ressaltar a grande importância da mobilização deste, para que siga corretamente os protocolos estipulados pelo profissional da área de nutrição veterinária, atingindo melhorias na saúde e qualidade de vida de seu cão.

\section{Referências bibliográficas}

Aptekmann, K. P., Suhett, W. G., Junior, A. F. M., Souza, G. B., Tristão, A. P. P. A., Adams, F. K., Aoki, C. G., Junior, R. J. G. P., Carciofi, A. C., \& Tinucci-Costa, M. (2014). Aspectos nutricionais e ambientais da obesidade canina. Ciência Rural, 44(11), 2039-2044.

Araújo, I. C. S., Furtado, A. P., Araújo, G. C. P., \& Rocha, C. G. (2018). Efeito do tipo de alimentação de cães saudáveis sobre análises clínicas e aspectos comportamentais. Arquivo Brasileiro de Medicina Veterinária e Zootecnia, 70, 689-698.

Araújo, L. F., \& Zanetti, M. A. (2019). Nutrição animal. Manole Ltda.

Brunetto, M. A., Nogueira, S., Sá, F. C., Peixoto, M., Vasconcellos, R. S., Ferraudo, A. J., \& Carciofi, A. C. (2011). Correspondência entre obesidade e hiperlipidemia em cães. Ciência Rural, 41(2), 266-271.

Camargo, M. A. (2017). Dislipidemias em animais (pp. 1-5).

Carciofi, A. C. (2005). Obesidade e suas conseqüências metabólicas e inflamatórias em cães e gatos.

Carciofi, A. C. (2008). Manejo nutricional do cão e do gato hospitalizado. In UNESP (Ed.), Apontamentos teóricos das disciplinas de Clínica das Doenças Carenciais, Endócrinas e Metabólicas e de Nutrição e Alimentação de Cães e Gatos. Universsidade de São Paulo.

Cardoso, M. J. L., Melussi, M., Costa, F. S., Fagnani, R., Holsback, L., Zacarias, A., \& Patelli, T. H. C. (2015). Canine hypoparathyroidism: case report. Arquivo Brasileiro de Medicina Veterinária e Zootecnia, 67, 353-357.

Conceição, P. S., Goslar, M. S., \& Silva, A. L. P. (2016). Avaliação da qualidade de dietas caseiras para cães obesos. Revista Eletrônica Biociências, Biotecnologia e Saúde, 6(15), 27-29.

Cordão, M. A., Diniz, S. J. B., Amaral, A. P., \& Lima, R. M. (2021). Medidas morfométricas de cães de diferentes raças e portes, submetidos às atividades físicas. Latin American Journal of Development, 3(1), 75-83.

Firmino, F. P., Silva, D. R. S., Cunha, G. L., Maciel, J. E. M., \& Espírito Santo, E. F. (2020). Comparação da sintomatologia da displasia coxofemoral entre cães obesos e não-obesos. Brazilian Journal of Development, 6(7), 46840-46850.

Garcia-Navarro, C. E., \& Pachaly, J. R. (1994). Manual de hematologia veterinária (Vol. 1). Varela.

Goslar, M. S., Conceição, P. D. S., Schulli, L., \& Palhano, A. L. (2016). Protocolo de emagrecimento canino com dieta caseira - Relato de caso. Revista Eletrônica Biociências, Biotecnologia e Saúde, 6(15), 276-278.

Guimarães, P. L. S. N. (2009). Conformação corporal e bioquímica sanguínea de cadelas adultas castradas alimentadas ad libitum. Universidade Federal de Goiáas.

Halfen, D. P., Oba, P. M., Duarte, C. N., Santos, J. P. F., Vendramini, T. H. A., Sucupira, M. C. A., Carciofi, A. C., \& Brunetto, M. (2017). Tutores de cães consideram a dieta caseira como adequada, mas alteram as fórmulas prescritas. Pesquisa Veterinária Brasileira, 37(12), 1453-1459.

Jericó, M. M., Kogika, M. M., \& Andrade Neto, J. P. (2015). Tratado de medicina interna de cães e gatos. Guanabara Koogan.

Kantek, C. E., \& Navarro, K. G. (2005). Manual de Hematologia Veterinária. São Paulo: Varela, 2. ed., 206 p. 
Laflamme, D. R. P. C. (1997). Development and validation of a body condition score system for dogs. Canine Practice, 22, 10-15.

Moreira, R. H. (2009). Hiperadrenocorticismo iatrogênico em cão: relato de caso. Revista Científica Eletrônica de Medicina Veterinária, 2(3), 1.

Muller, J. D. C. M., \& Maicon, P. E. S. (2008). Adaptação do índice de massa corporal humano para cães. Ciência Rural, 38(4), 1038-1043.

NRC. (2006). Nutrient requirements of dogs and cats. The National Academies Press.

Rebar, A. H., MacWilliams, P. S., Feldman, B. F., Metzger, F. L., Pollock, R. V. H., Roche, J., Hagiwara, M. K., \& Brandão, L. P. (2003). Guia de hematologia para cães e gatos. Roca.

Rodrigues, L. F. (2011). Métodos de avaliação da condição corporal em cães. In Universidade Federal de Goiás (pp. 1-34). Universidade Federal de Goiás.

Roque, N., José, V. A., Aquino, A. A., Alves, M. P., \& Saad, F. M. O. B. (2006). Utilização da fibra na nutrição de cães. Boletim Agropecuário, 70, 1-13.

Rosa, V. M., Carniato, C. H. O., \& Campanerutti, G. (2011). Hiperadrenocorticismo em cães. In Encontro Internacional de Produção Científica. CESUMAR.

Saad, F. M. O. B., \& França, J. (2010). Alimentação natural para cães e gatos. Revista Brasileira de Zootecnia, 39(1), 52-59.

Silva, S. F., Brito, A. K. F., Freire, B. A. A., Sousa, L. M., \& Pereira, I. M. (2017). Obesidade canina: Revisão. PUBVET, 11, 313-423.

Histórico do artigo:

Recebido: 5 de março de 2021

Aprovado: 5 de abril de 2021
Licenciamento: Este artigo é publicado na modalidade Acesso Aberto sob a licença Creative Commons Atribuição 4.0 (CC-BY 4.0), a qual permite uso irrestrito, distribuição, reprodução em qualquer meio, desde que o autor e a fonte sejam devidamente creditados. 